\title{
ПРОГНОСТИЧЕСКОЕ ЗНАЧЕНИЕ ГЛИКЕМИЧЕСКОГО КОНТРОЛЯ ПРИ ИНФАРКТЕ МИОКАРДА У БОЛЬНЫХ САХАРНЫМ ДИАБЕТОМ
}

\author{
Коротина М.А., Починка И.Г., Стронгин Л.Г.
}

ФГБОУ ВО «Приволжский исследовательский медицинский университет» Минздрава России, Нижний Новгород

ЦЕЛЬ: оценить влияние гликемического контроля во время госпитализации по поводу инфаркта миокарда (ИМ) на прогноз у пациентов с сахарным диабетом (СД).

МАТЕРИАЛЫ И МЕТОДЫ: в исследование включены больные ИМ, последовательно госпитализированные в Региональный сосудистый центр на базе ГБУЗ НО ГКБ№13 Нижнего Новгорода в течение 200 дней с 01/01/2018 по 19/07/2018 года. Из 927 пациентов с ИМ 237 страдали СД (26\%), из них в 37 случаях СД выявлен впервые. Среди больных СД: средний возраст составил 68土11 лет, женщины составили 60\% группы (141 случай); в 5 случаях (2\%) был СД 1 типа и в 232 случаях (98\%) СД 2 типа; ИМ с подъемом сегмента ST имелся у 134 пациентов (57\%), в 103 случаях (43\%) - ИМ без элевации ST. В 173 случаях (73\%) проведена селективная коронарография, чрескожное коронарное вмешательство (ЧКВ) выполнено у 136 больных (57\%). Непрерывная внутривенная инфузия инсулина в 1 сутки проводилась в 4 случаях (2\%), подкожная базис-болюсная инсулинотерапия применялась в 142 случаях (60\%), терапия пероральными сахароснижающими препаратами применялась у 96 больных (68\%), у 16 человек (7\%) терапия не назначалась. Медиана продолжительности госпитализации - 11 дней. Медиана количества измерений гликемии в течение госпитализации - 15 раз. Отдаленный исход установлен в 146 случаях. Медиана времени наблюдения - 526 дней.

РЕЗУЛЬТАТЫ: у больных СД гликемия при поступлении составила 13,6士5,9 ммоль/л, перед выпи-

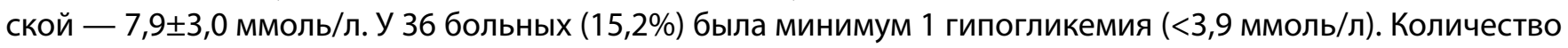
измерений гликемии менее 6,1 ммоль/л составило 13\%, в диапазоне 6,1-10,0 ммоль/л - 49\%, более 10,0 ммоль/л - 38\% измерений. Более 50\% измерений в пределах 6,1-10,0 ммоль/л имели 105 больных (44\%), >10,0 ммоль/л - 76 больных (32\%).

Из 697 пациентов без СД смерть в стационаре наступила в 38 случаях (летальность - 5,5\%), из 237 больных СД - в 34 случаях (летальность - 14,3\%), p<0,001 (Хи-квадрат Pearson). Из 146 больных СД с известным отдаленным исходом смерть зарегистрирована в 53 случаях (34 в стационаре и 19 случаев после выписки). Из 93 выживших пациентов - в 45 случаях (48\%) более 50\% измерений находились в диапазоне 6,1-10,0 ммоль/л, из 53 случаев со смертельным исходом таковых оказалось 13 больных (25\%), p=0,006 (Хи-квадрат Pearson). Из 58 пациентов, имевших более 50\% измерений в диапазоне 6,1-10,0 ммоль/л, умерли 13 больных (22\%), из 60 пациентов, имевших более 50\% измерений в диапазоне >10,0 ммоль/л, смерть наступила в 30 случаях (50\%), р<0,001(Хи-квадрат Pearson). Выявлена прямая корреляция между долей измерений в диапазоне 6,1-10,0 ммоль/л и временем дожития $\mathrm{r}=0,38$ ( $\mathrm{p}<0,001$, Spearmen). B многофакторной модели, включающей возраст >80 лет (ОР 2,96, 95\% ДИ 1,48-5,91), рСКФ<45 мл/мин (ОР 2,02, 95\% ДИ 1,16-3,52), ФВ<40\% (ОР 2,37, 95\% ДИ 1,28-4,40) и выполнение ЧКВ (ОР 0,27, 95\% ДИ 0,13-0,56), попадание более 50\% измерений гликемии в диапазон 6,1-10,0 ммоль/л сопровождается достоверным снижением риска смертельного исхода в течение 1,5 лет - ОР составило 0,33, 95\% ДИ 0,17-0,65 (регрессионная модель Сох).

ВывОДЫ: при ИМ у больных СД попадание более 50\% измерений гликемии в диапазон 6,1-10,0 ммоль/л ассоциируется с меньшей частотой наступления смерти в течение 1,5 лет. 